\title{
Article \\ The Effect of Mirid Density on Volatile-Mediated Foraging Behaviour of Apolygus lucorum and Peristenus spretus
}

\author{
Han Chen (D), Honghua Su, Shuai Zhang, Tianxing Jing, Zhe Liu and Yizhong Yang * \\ College of Horticulture and Plant Protection, Yangzhou University, Yangzhou 225007, China; \\ levyashin276@163.com (H.C.); susugj@126.com (H.S.); shuaizhang@yzu.edu.cn (S.Z.); jingtx@yzu.edu.cn (T.J.); \\ zhe_liu9208@163.com (Z.L.) \\ * Correspondence: yzyang@yzu.edu.cn
}

\section{check for} updates

Citation: Chen, H.; Su, H.; Zhang, S. Jing, T.; Liu, Z.; Yang, Y. The Effect of Mirid Density on Volatile-Mediated Foraging Behaviour of Apolygus lucorum and Peristenus spretus. Insects 2021, 12, 870. https://doi.org/ $10.3390 /$ insects 12100870

Academic Editors: José Carlos Franco, Arturo Cocco, Stefano Speranza,

António Onofre Costa

Miranda Soares and Lucia Zappala

Received: 4 August 2021

Accepted: 16 September 2021

Published: 25 September 2021

Publisher's Note: MDPI stays neutral with regard to jurisdictional claims in published maps and institutional affiliations.

Copyright: (c) 2021 by the authors. Licensee MDPI, Basel, Switzerland. This article is an open access article distributed under the terms and conditions of the Creative Commons Attribution (CC BY) license (https:/ / creativecommons.org/licenses/by/ $4.0 /)$.
Simple Summary: Since the widespread adoption of Bt cotton in the late 1990s, the green mirid bug, Apolygus lucorum (Hemiptera: Miridae), has become one of the most important pests in cotton fields and some other crops. To manage this destructive pest, Peristenus spretus (Hymenoptera: Braconidae) has been tested in augmentative biological control. In this study, after cotton plants were damaged by different densities of $A$. lucorum, the behavioral responses of A. lucorum and P. spretus to cotton plants volatiles were evaluated, and the quality and quantity of volatiles from cotton plants were analyzed. The results demonstrated that HIPVs emitted by plants in response to A. lucorum could be influenced by the pest density and could be identified by P. spretus as a signal of the host. Our results would help understand how P. spretus plays a role in biological control against A. lucorum.

Abstract: Plants would release herbivore-induced plant volatiles (HIPVs) to repel herbivores and attract natural enemies after being damaged by herbivores. In this study, after cotton plants were damaged by different densities of Apolygus lucorum, the behavioral responses of A. lucorum and Peristenus spretus to cotton plants volatiles were evaluated, and the quality and quantity of volatiles from cotton plants were analyzed. Only when cotton plants were damaged by four bugs did both A. lucorum and P. spretus show an obvious response to damaged cotton plants, which indicates that cotton defense is correlated with pest density. The collection and analysis of volatiles reveals that the increase in pest density results in the emission of new compounds and an increase in the total number of volatiles with an alteration in proportions among the compounds in the blend. These changes in volatile profiles might provide wasps and mirids with specific information on host habitat quality and thus could explain the behavioral responses of parasitoids and pests.

Keywords: behavior; pest; natural enemy; HIPVs; density

\section{Introduction}

Many herbivores attacked plants during their growth; however, plants were not merely passive victims of herbivore attacks, and a variety of mechanisms that contributed to their resistance would be reconfigured to tolerate the damage and stresses of natural ecosystems [1-5]. Different chemical defense responses were induced by herbivory arthropods in different plants [6]. The important life-history parameters of herbivory arthropods such as development time, fecundity, longevity, or survival were negatively affected by some non-volatile toxic secondary metabolites. Meanwhile, subsequent repellency of herbivores and attraction of natural enemies were both determined by the herbivore-induced plant volatiles (HIPVs) [7-10].

HIPVs were always composed of two classes [11]. The first class was called constitutive volatile compounds, which mainly comprised green leaf volatiles (six-carbon alcohols, aldehydes, and acetates) emitting immediately from ruptured plant cells after mechanical damage [12-14]. The second class was called inducible volatile compounds, which have 
always been produced as a result of insect damage or oviposition $[15,16]$. They were emitted from the site of the wound and lasted for a period after herbivore removal $[17,18]$.

HIPVs always play crucial roles in tritrophic interactions between plants, herbivores, and carnivores, for the timely emission of specific HIPVs determined the effectiveness of volatile-mediated defense response. Previous studies have demonstrated that HIPVs affect behaviors of herbivorous or carnivorous arthropods [7,19,20]. However, although different HIPVs might share many compounds, the amount and composition of HIPVs were still different among plant species [21]. In addition, the amount and constitution of HIPVs were also influenced by pest density and were specific to each plant-pest-natural enemy association [22,23].

A lot of prior efforts have shown that herbivore density influences the intensity of feeding damage in to modulate interactions between plants and insects; meanwhile, the attractiveness of herbivore-infested plants to parasitoids and predators were also changed $[8,14]$. However, the knowledge about how different herbivore densities caused dynamic changes in HIPVs composition and, thus, how to change the behaviors of pests and natural enemies were still limited.

Since the widespread adoption of transgenic Bacillus thuringiensis $(\mathrm{Bt})$ cotton in the late 1990s, the green mirid bug, Apolygus lucorum Meyer-Dür (Hemiptera: Miridae), has become one of the most important pests in cotton fields and some other crops [24]. To manage this destructive pest, the native endoparasitoid Peristenus spretus Chen et van Achterberg (Hymenoptera: Braconidae) has been used in augmentative biological control. A series of studies confirmed that P. spretus was attracted by A. lucorum damaged cotton plant, and the parasitism rate was about $30 \%$. This indicated that $P$. spretus had great potential in biological control against $A$. lucorum [25].

In order to better understand the impact of pest density changes on HIPVs and the response of A. lucorum and P. spretus to cotton plants infestation by A. lucorum, the HIPVs from cotton plants damaged by A. lucorum under different densities were collected. Our objectives were (1) to investigate whether the behavior of A. lucorum and P. spretus varied substantially with herbivore densities and (2) to analyze the component complexity in HIPVs from different densities.

\section{Materials and Methods}

\subsection{Insects and Cotton Plants}

For the experiment, the colonies of A. lucorum and P. spretus were established. Both colonies were provided by the laboratory at the Langfang Experiment Station, Chinese Academy of Agricultural Sciences (CAAS), Hebei Province, China $\left(39.53^{\circ} \mathrm{N}, 116.70^{\circ} \mathrm{E}\right)$. The A. lucorum was reared on fresh green bean (Phaselus vulgaris L.) pod and maize (Zea mays L.) in the laboratory of Yangzhou University at $25 \pm 1{ }^{\circ} \mathrm{C}$ with $60 \pm 10 \% \mathrm{RH}$ and a 14:10 (L:D) photoperiod (the light period starts at 5:00 a.m.) in a climate-controlled rearing chambers [26]. The P. spretus was also reared in the growth chamber of Yangzhou University at $25 \pm 1{ }^{\circ} \mathrm{C}$ with $65 \pm 5 \% \mathrm{RH}$ and a $14 \mathrm{~h}$ light:10 $\mathrm{h}$ dark (the light period starts at 5:00 a.m.). They were reared on the second instar nymphs of A. lucorum and maintained with a $10 \%$ honey solution [27].

The seeds of transgenic Bt cotton (var. SGK321) were provided by the Biotechnology Research Institute of CAAS (Beijing) and grown in the greenhouse of Yangzhou University. All the plants were enclosed in a nylon cage with 60 mesh to prevent herbivore damage. After 8 leaves came out, similar and healthy plants were collected for experiments.

\subsection{Cotton Plants Treatment}

The cotton plants were individually placed in the collection apparatuses for 1 day before volatile collection to adapt to the new environmental condition. Before treatment, 3rd-stage-old nymphal A. lucorum specimens were starved for $8 \mathrm{~h}$ and then carefully transferred to true leaves of cotton by a soft brush. The following treatments were used: control undamaged plant (CK) and each plant infested with 1 miridae (1 bug), 2 miridae 
( 2 bugs), 4 miridae ( 4 bugs) and 8 miridae ( 8 bugs). The experiment started at 10:00 a.m., and after $24 \mathrm{~h}$ of initial $A$. lucorum infestation, the nymphals were removed. All densities treatments were replicated four times.

\subsection{Behavioral Assays}

Y-tube olfactometer bioassays were conducted to evaluate the behavior responses of $A$. lucorum and P. spretus to cotton plants' volatiles. The equipment was similar to that of Xiu with slightly modified procedures [20]. Briefly, a glass jar (capacity: $10 \mathrm{~L}$ ) was connected to each of the two arms of the Y-tube olfactometer. Each glass contained an air inlet tube connecting a vacuum pump (QC-1, Beijing Institute of Labor Instrument, Beijing, China) and an outlet tube connecting to the olfactometer arm. The vacuum pump pushed air through activated charcoal and an Erlenmeyer flask filled with distilled water. Airflow through each arm was maintained at $1 \mathrm{~L} / \mathrm{min}$. Different treatments of cotton plants were placed inside the glass jar for experiments.

All the $A$. lucorum-induced cotton plants volatiles $(1,2,4$, and 8 bugs) were tested against control volatiles (healthy). Apolygus lucorum or P. spretus was released individually at the entrance of the Y-tube olfactometer and was allowed only $5 \mathrm{~min}$ to respond to the two odor sources. The number of insects choosing each of the odors was recorded. Sixty females of P. spretus were tested from 10:00 a.m. to 14:00 p.m., while sixty adults of $A$. lucorum were tested from 17:00 p.m. to 21:00 p.m. because the feeding and parasitic behaviors happened during these two periods in the field, respectively [26,27]. All parasitoids and pests used in the experiments were $2-4$ days old.

\subsection{Headspace Volatile Collection and Analysis}

The collection apparatus for volatile emitted by healthy and damaged cotton plants involved a dynamic headspace collection system [28]. Briefly, the plant's pot was removed, and the roots with soil were packed in aluminum foil. After that, the plant was transferred to a 10-L glass jar. Before trapping volatile, the system was purged at a flow rate of $1 \mathrm{~L} / \mathrm{min}$ with a vacuum pump (QC-1, Beijing Institute of Labor Instrument, Beijing, China) for more than 30 min. During the volatile collection, activated charcoal purified air was pumped through Teflon tubing into the system at a flow rate of $1 \mathrm{~L} / \mathrm{min}$ through a glass tube (length: $89 \mathrm{~mm}$, inner diameter: $5 \mathrm{~mm}$ ) filled with $100 \mathrm{mg}$ Tenax TA (60/80 mesh; Sigma-Aldrich, Oakville, ON, Canada).

The headspace volatiles from plants was collected for a $4 \mathrm{~h}$ period from 10:00 a.m. to 14:00 p.m. and 17:00 p.m. to 21:00 p.m., respectively. After collection, the volatiles were extracted with $400 \mu \mathrm{L}$ n-hexane (Sinopharm Chemical Reagent Co. Ltd., Shanghai, China) and $4 \mu \mathrm{g}$ n-octane (Aladdin Co. Ltd., Shanghai, China) was added to each sample as an internal standard.

The volatile samples were then analyzed using a coupled gas chromatography-mass spectrometry (GC-MS) instrument (Trace ISQ, Thermofisher, CA, USA) equipped with a DB-5 MS column $(30 \mathrm{~m} \times 0.25 \mathrm{~mm} \times 0.25 \mu \mathrm{m})$. Sample injection was operated splitlessly at $200{ }^{\circ} \mathrm{C}$, and helium was used as the carrier gas with a flow rate of $1 \mathrm{~mL} / \mathrm{min}$. The column temperature was maintained at $40{ }^{\circ} \mathrm{C}$ for $1 \mathrm{~min}$ and then programmed from $5{ }^{\circ} \mathrm{C} / \mathrm{min}$ to $210^{\circ} \mathrm{C}$, and finally from $15^{\circ} \mathrm{C} / \mathrm{min}$ to $250{ }^{\circ} \mathrm{C}$. The ionization was by electron impact (70 eV, source temperature $220^{\circ} \mathrm{C}$ ).

The volatile components were identified based on the following: (I) comparing their retention times and mass spectra to authentic standards; (II) comparing their mass spectra and retention indices calculated relatively to the C8-C20 n-alkanes on the DB-5 column; (III) comparing their mass spectra in the mass spectra library NIST 2014 (National Technical Information Services, Springfield, VA, USA). The amounts of individual volatile compounds were quantified relative to the internal standard. 


\subsection{Data Analysis}

For Y-tube olfactometer assays, the null hypothesis was that pest and natural enemy both showed no preference for each arm (i.e., 50:50 response). The results were analyzed by using a $\chi^{2}$ goodness-of-fit test, and the unresponsive individuals were not included. Statistical comparisons of volatiles collected from different treatments were carried out by ANOVA followed by the Tukey's HSD test using the software SPSS 25.0 (IBM SPSS, Somers, NY, USA), and a significance level of $p<0.05$ was applied. The partial least-squares discriminate analysis (PLS-DA) which defined latent variables as linear combinations of the original manifest variables and calculated to maximize the covariance with the response variables was processed by the software SIMCA-P 14.0 (Umetrics AB, Umeå, Sweden) to test the differences in the cotton plants volatiles under different pest densities. Variable importance for the projection (VIP) value of each compound was also calculated by the software SIMCA-P 14.0, and compounds with a value greater than 1 were considered as contributing separation between each treatment [29].

\section{Results}

\subsection{Behavioral Responses of Mirids and Parasitoids to Cotton Plants Volatiles}

In dual-choice bioassays, there was no significant difference in adult mirid's preference between healthy cotton plants and the cotton plants damaged by one mirid bug $\left(\chi^{2}=0.594\right.$, $d f=1, p=0.441)$. However, the adult mirid exhibited a significant response to healthy cotton plants as compared with the cotton plants fed by two or eight mirid bugs $\left(\chi^{2}=5.588\right.$, $d f=1, p=0.018 ; \chi^{2}=4.1, d f=1, p=0.043$ ). In addition, the mirid adults showed a highly significant response to healthy cotton plants when compared with those damaged by four mirid bugs $\left(\chi^{2}=15.395, d f=1, p<0.01\right)$ (Figure 1a).

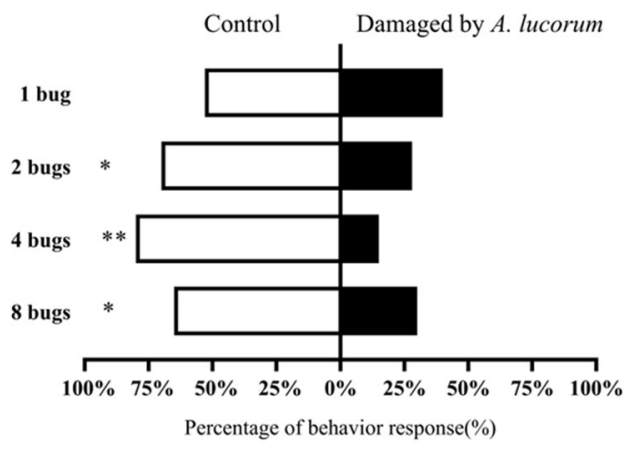

(a)

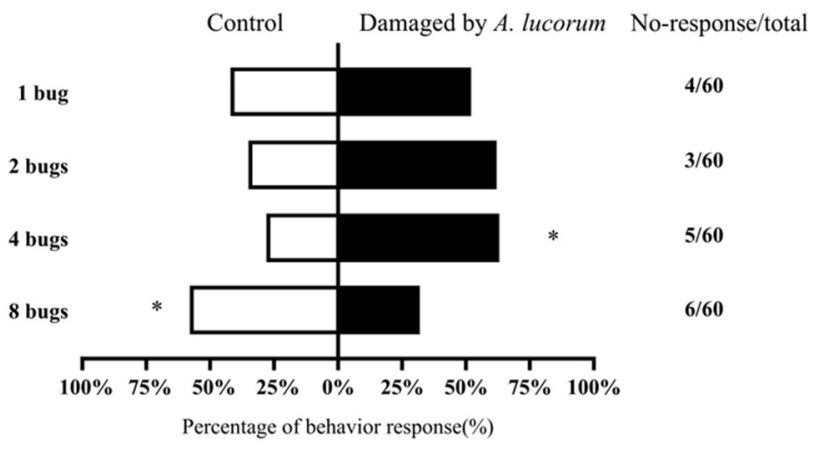

(b)

Figure 1. Behavioral responses of insects to damaged cotton plants or health cotton plants volatiles in the $Y$-tube olfactometer assays. (a) behavior responses of A. lucorum; (b) behavior responses of P. spretus. The asterisks were based on the $\chi^{2}$ analysis. "**" denoted difference at the $p<0.05$, and " $* * *$ denoted difference at the $p<0.01$.

The volatiles emitted from cotton plants damaged by four mirid bugs were more attractive to the $P$. spretus adult than those from uninfested cotton plants $\left(\chi^{2}=4.328, d f=1\right.$, $p=0.037$ ) while there was no significant difference in the volatiles emitted from cotton plants damaged by one mirid bug or two mirid bugs compared with those from undamaged treatment $\left(\chi^{2}=0.333, d f=1, p=0.564 ; \chi^{2}=2.286, d f=1, p=0.131\right)$. It was worth noting that the adult wasp showed a significant response to healthy cotton plants as compared with the cotton plants fed by eight mirid bugs $\left(\chi^{2}=4.022, d f=1, p=0.045\right)$ (Figure $\left.1 b\right)$.

\subsection{Volatile Cotton Emission Induced by Different Densities of A. lucorum}

From 17:00 p.m. to 21:00, p.m. only 20 volatile compounds were detected from undamaged cotton plants, whereas 27 volatile compounds were detected from the cotton plants damaged by one mirid bug. The number of compounds increased to 31 when the 
cotton plants were damaged by 4 or 8 mirid bugs, while 30 compounds were found in volatile from cotton plants damaged by two mirid bugs (Table S1). The amounts of HIPVs released at the peak when the cotton plants were damaged by two or four mirid bugs and their total amount were both significantly higher than the rest treatments. The amount from the cotton damaged by eight bugs was also significantly higher than that from undamaged cotton plants or that from cotton plants damaged by 1 mirid bug, while there was no significant difference between undamaged cotton plants and cotton plants damaged by one mirid bug $(F=43.862, p<0.05)$ (Figure $2 \mathrm{a})$.

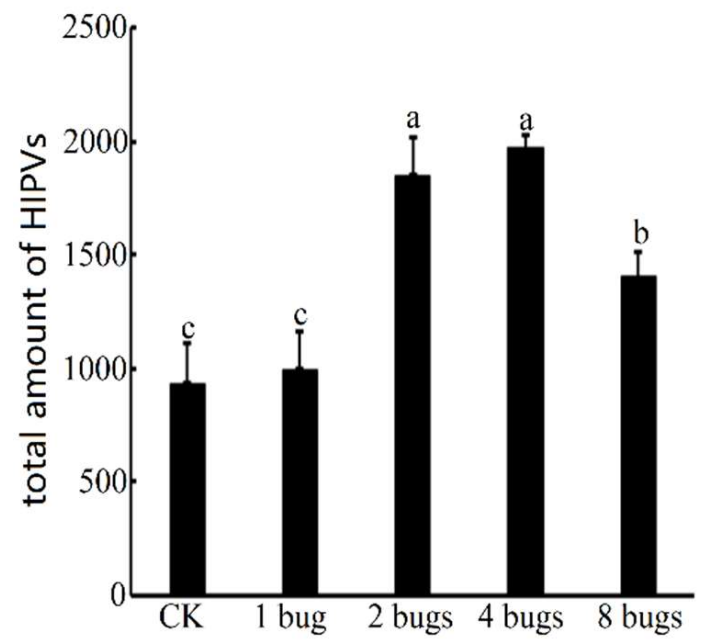

(a)

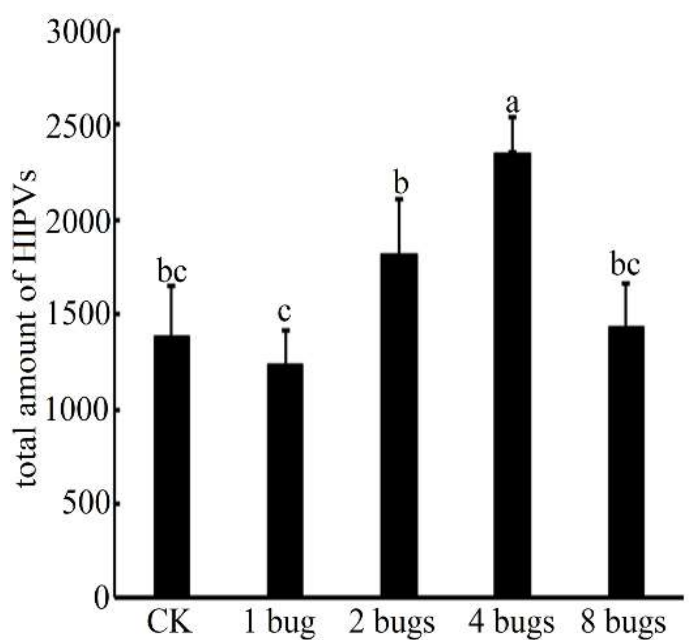

(b)

Figure 2. Total amount of HIPVs released from cotton plants and showed by Mean \pm SE. Amounts with different letters were significantly different at the 5\% level by Tukey's HSD test. (a) Released at the period from 17:00 p.m. to 21:00 p.m.; (b) Released at the period from 10:00 a.m. to 14:00 p.m.

After a projection of partial least squares-discriminant analysis (PLS-DA) the contents of detected HIPVs showed a clear separation between uninfested plants and damaged by more than one mirid bug. The first two significant PLS components explained $54.8 \%$ and $31.3 \%$ of the total variance, respectively (Figure 3a). The first component showed a clear separation between undamaged control cotton plants and cotton plants damaged by two or four mirid bugs, while the second component separated HIPVs released from damaged by eight mirid bugs versus the other treatments. However, the first two components could not separate the healthy plant from the plant damaged by one mirid. The plant damaged by two mirid bugs could not be separated from that damaged by four mirid bugs. In this model, the following volatile compounds dodecane, $(E)$ - $\beta$-ocimene, decanal, $(+)-\delta$-cadinene, nonanal, linalool oxide, DMNT, 1,3-xylene, octanal, hexenyl butyrate and (E)- $\alpha$-caryophyllene with VIP values $\geq 1.0$ contributed most to the separation between the undamaged and A. lucorum-damaged volatiles (Figure 4a).

From 10:00 a.m. to 14:00 p.m., a total of 21 volatile compounds were also collected from undamaged cotton plants, whereas 27 were detected from the cotton plants were damaged by one mirid bug. The number of compounds all increased to 31 when the cotton plants damaged by two, four, or eight mirid bugs (Table S2). Analysis of the relative quantities of volatile compounds showed that the total amount of volatiles from the cotton plants damaged by four mirid bugs was significantly higher than other treatments; meanwhile, the amount from cotton plants damaged by two mirid bugs was also significantly higher than the other treatments. However, the number of undamaged cotton plants was not significantly different from the cotton plants damaged by one mirid bug or eight mirid bugs $(F=14.285, p<0.05)$ (Figure $2 b)$. 


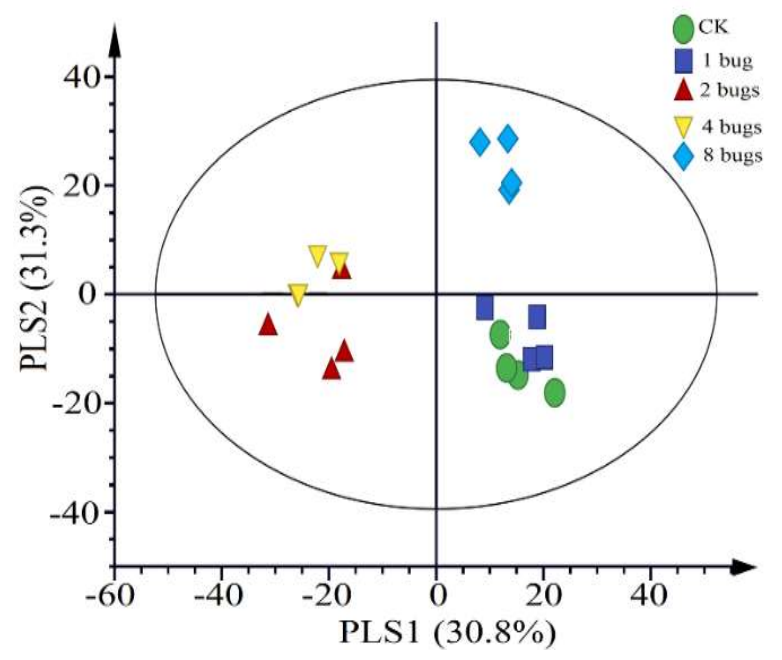

(a)

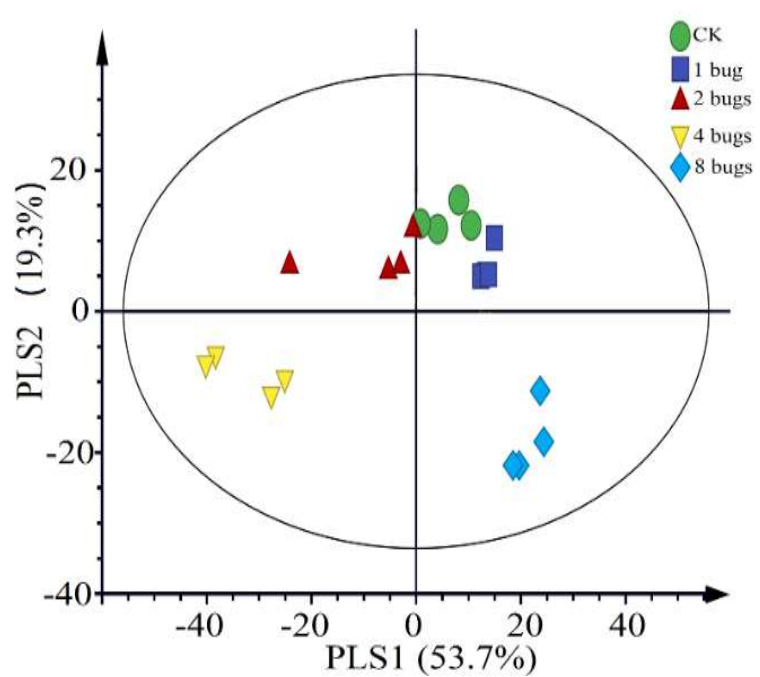

(b)

Figure 3. Partial least squares discriminant analysis (PLS-DA) of cotton plants volatile compounds. The cotton plants were either uninfested (Control), infested with one miridae (one bug), two miridae (two bugs), four miridae (four bugs), or eight miridae (eight bugs). The score plot displays the grouping pattern according to the first two components, and the ellipse defines Hotelling's T2 confidence interval (95\%) for the observations. (a) HIPVs collected at the period from 17:00 p.m. to 21:00 p.m.; (b) HIPVs collected at the period from 10:00 a.m. to 14:00 p.m.

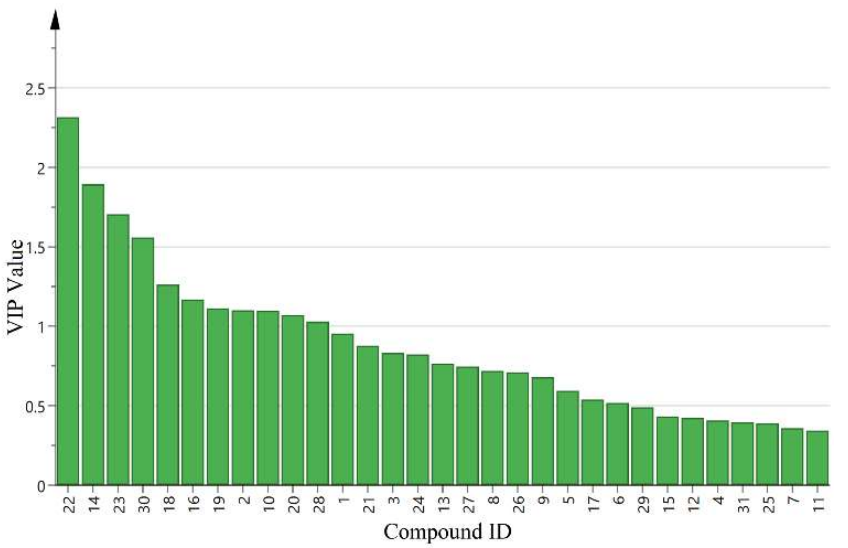

(a)

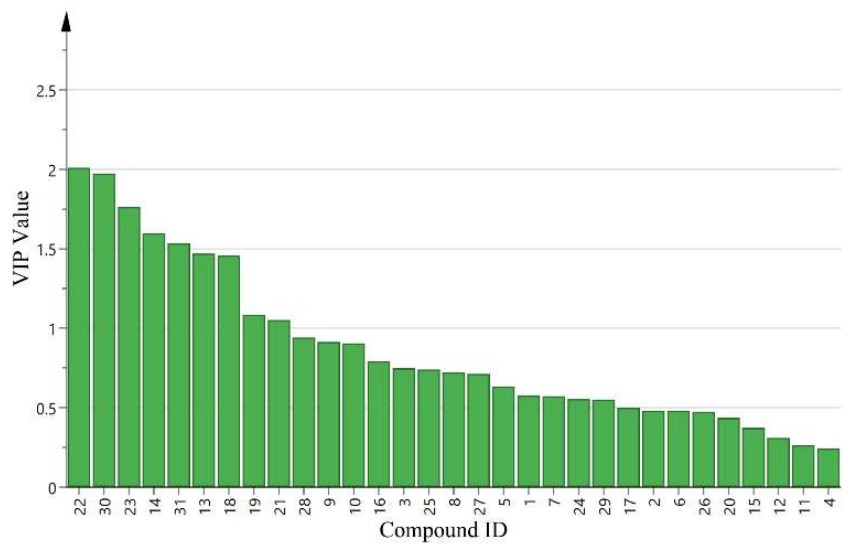

(b)

Figure 4. VIP value of cotton plants volatile compounds. (a) HIPVs collected at the period from 17:00 p.m. to 21:00 p.m.; (b) HIPVs collected at the period from 10:00 a.m. to 14:00 p.m. Compounds ID: 1. ethylbenzene; 2. 1,3-xylene; 3. nonane; 4. $\alpha$-pinene; 5. Benzaldehyde; 6. (E)-2-hexenal; 7. $\beta$-myrcene; 8. 6-methyl-5-hepten-2-one; 9. decane; 10. octanal; 11. terpinene; 12 . limonene; 13. (Z)-3-hexen-1-yl acetate; 14 . (E)- $\beta$-ocimene; 15 . acetophenone; 16 . linalool oxide; 17. linalool; 18. nonanal; 19. DMNT,(3E)-4,8-dimethyl-1,3,7-nonatriene; 20. hexenyl butyrate; 21. (4Z)-4-hexenyl butylate; 22 . dodecane; 23. decanal; 24. (2E)-2-hexen-1-yl propanoate; 25. tridecane; 26. unknown; 27. (E)- $\beta$-caryophyllene; 28. (E)- $\alpha$-caryophyllene; 29. $\alpha$-farnesene; 30 . (+)- $\delta$-cadinene; 31 . nerolidol.

Partial least squares projection to latent structures-discriminant analysis (PLS-DA) showed a clear separation between undamaged plants and plants damaged by more than one mirid bugs (Figure 3b). The first two significant PLS components explained $53.4 \%$ and $20.4 \%$ of the total variance, respectively. At this time, the dodecane, $(E)$ - $\beta$-ocimene, decanal, (+)- $\delta$-cadinene, nerolidol, (Z)-3-hexen-1-ol acetate, nonanal, (Z)-butanoic acid, 4-hexenyl ester, and DMNT with VIP values $\geq 1.0$ contributed most to the separation (Figure $4 \mathrm{~b}$ ). 


\section{Discussion}

When plants perceived pest feeding damage, a series of defensive mechanisms would be activated to promote plant fitness, and therefore herbivores were repelled while the natural enemies were attracted $[4,30]$. In this study, we investigated the response of $P$. spretus and A. lucorum to chemical cues induced by different densities of A. lucorum. Our analysis showed that both the P. spretus and A. lucorum had no obvious preferences for the volatiles from the plant damaged by one bug. Only when the plant was fed by four bugs did the P. spretus show an obvious preference, and the A. lucorum show an obvious repellency, indicating that defense is activated. This result suggests that there is a positive relationship between the degree of induced resistance in Bt cotton and the density of $A$. lucorum in a certain range.

The pest density was proved to influence the behaviors of herbivorous or carnivorous arthropods in previous studies. For example, after the cotton or lima bean was damaged by Spodoptera littoralis Boisd under different densities, S. littoralis preferred the plants already damaged by less density or healthy plant [8,31]. A similar conclusion was drawn after testing the behavior of Plutella xylostella $\mathrm{L}$. to the cabbage damaged by the same pest under different densities [32]. Besides herbivores, carnivores were also influenced by pest density. Phytoseius persimilis Athias-Henriot would not be attracted to kidney beans which were damaged by 30 Tetranychus urticae Koch adults until the number reached more than 100 [33]. Similarly, the parasitoid Cotesia glomerata L. was only attracted to the Brussels sprouts L. damaged by Pieris brassicae L. at a high level which indicates that systemic induction does not occur at low-level herbivore infestation [18]. Moreover, when the eggplants were attacked by Thrips palmi Karny or Tetranychus kanzawai Kishida, the predators Wollastoniella rotunda Yasunaga and Miyamoto preferred the odor from the eggplants infested with more pests [34].

The different amounts of HIPVs released in response to the level of infestation were also proved in previous studies [35,36]. In this study, from 10:00 a.m. to 14:00 p.m., the total amount of HIPVs did not significantly increase until the cotton was infested by at least two bugs and the PLS-DA of volatiles revealed a clear separation between cotton damaged by more than one bug versus healthy cotton. From 17:00 p.m. to 21:00 p.m., the total amount of HIPVs significantly increased when the cotton was damaged by four bugs, and the PLS-DA of volatiles only revealed a clear separation between cotton damaged by four or eight bugs versus healthy cotton. This difference might be caused by different rhythm emissions of volatile compounds throughout the day. This phenomenon has been confirmed in other experiments [37]. After an analysis of the chemical components, most of the significantly increased volatile compounds and new compounds were identified as the terpenes, which have been proved to play the most important role in the defense of plants against $A$. lucorum in numerous studies $[37,38]$. For instance, $\beta$-myrcene, limonene, and $(E)$ - $\beta$-ocimene were proved to affect the behavior of A. lucorum and P. spretus; the $(+)-\delta$-cadinene was catalyzed to the gossypol, a kind of specialized secondary metabolite that confers resistance to A. lucorum when cotton plants perceived damage [39]. Similar to the behavioral changes, most terpenes were only detected from cotton plants damaged by more than one bug and reached a peak when cotton plants were damaged by four bugs. These results imply that an adequately strong elicitation signal which exceeds the damage level threshold was necessary for the inducible resistance. There was a perception that whether plants metabolically reorganized in response to herbivores by inducing the production of defensive materials and reducing major cell processes involved in growth and photosynthesis was determined by the herbivore's pressures and the cost of the defense $[40,41]$. Recently a series of studies proved this hypothesis in Arabidopis thaliana L., Brassica nigra L., and Zea mays L. after a pest attack [30,42,43].

In addition, the P. spretus showed an obvious preference for the undamaged cotton plants when the cotton plants were fed by eight bugs. It has been initially assumed that the density of herbivores was too high for the plant, so that after pest damage, the plant was not suitable for larval development anymore. Lots of studies have proved that the 
mother would select the host, which minimizes neonatal mortality because they are at the most sensitive stage of host quality [44,45]. For example, the Diaeretiella rapae (McIntosh) only preferred aphid-induced to non-induced plant volatiles at low aphid infestation level, whereas they did not discriminate between volatiles at high aphid infestation level [43]; Anagrus nilaparvatae (Pang et Wang) were also only attracted by plant damaged by less than 10 brown planthoppers [46]. A further chemical analysis showed that compared to the cotton plants damaged by four bugs the plant infested by eight bugs did not release any new compound. However, the total amount of HIPVs and the proportions of chemicals in the blend were both changed during the entire infestation. This result implies that the behavior of $P$. spretus might be determined by a blend of multiple compounds and their content ratios in HIPVs, which are considered as a signal from cotton plants to locate hosts. Further investigation on olfactory response and foraging behaviors of A. lucorum and $P$. spretus to mixture volatiles should be conducted to test our hypothesis.

In brief, the current study demonstrated that HIPVs emitted by plants in response to A. lucorum could be influenced by pest density and could be identified by P. spretus as a signal of the host. Our results would help to deeply understand how P. spretus plays a role in biological control against A. lucorum.

Supplementary Materials: The following are available online at https: / www.mdpi.com/article / 10.3390 /insects12100870/s1, Table S1: Volatile compounds released by differently infested cotton plants collected from 17:00 p.m. to 21:00 p.m.; Table S2: Volatile compounds released by differently infested cotton plants collected from 10:00 p.m. to 14:00 p.m.

Author Contributions: Conceptualization, H.C.; Data curation, H.C.; Formal analysis, H.C. and H.S.; Funding acquisition, Y.Y.; Investigation, H.C., H.S. and S.Z.; Methodology, H.C., H.S. and S.Z.; Project administration, H.C., H.S. and S.Z.; Resources, H.C.; Software, H.C.; Supervision, S.Z. and T.J.; Validation, H.C., T.J. and Z.L.; Visualization, H.C. and Z.L.; Writing-original draft, H.C. and H.S.; Writing-review and editing, H.C., H.S. and Y.Y. All authors have read and agreed to the published version of the manuscript.

Funding: This research was funded by the National Key Research and Development Program of China (2017YFD0201907).

Data Availability Statement: The data presented in this study are available in Supplementary materials.

Acknowledgments: We are very grateful to Langfang Experiment Station, Chinese Academy of Agricultural Sciences for giving us the insects and cotton seeds.

Conflicts of Interest: The authors declare no conflict of interest.

\section{References}

1. Birkett, M.A.; Campbell, C.A.; Chamberlain, K.; Guerrieri, E.; Hick, A.J.; Martin, J.L.; Matthes, M.; Napier, J.A.; Pettersson, J.; Pickett, J.A.; et al. New roles for cis-jasmone as an insect semiochemical and in plant defense. Proc. Natl. Acad. Sci. USA 2000, 97, 9329-9334. [CrossRef]

2. Thaler, J.S.; Karban, R.; Ullman, D.E.; Boege, K.; Bostock, R.M. Cross-talk between jasmonate and salicylate plant defense pathways: Effects on several plant parasites. Oecologia 2002, 131, 227-235. [CrossRef]

3. Dicke, M.; van Loon, J.J.; Soler, R. Chemical complexity of volatiles from plants induced by multiple attack. Nat. Chem. Biol. 2009, 5, 317-324. [CrossRef] [PubMed]

4. Dicke, M.; Baldwin, I.T. The evolutionary context for herbivore-induced plant volatiles: Beyond the 'cry for help'. Trends Plant Sci. 2010, 15, 167-175. [CrossRef]

5. Hare, J.D. Ecological role of volatiles produced by plants in response to damage by herbivorous insects. Annu. Rev. Entomol. 2011, 56, 161-180. [CrossRef] [PubMed]

6. Rodriguez-Saona, C.; Crafts-Brandner, S.J.; Canas, L.A. Volatile emissions triggered by multiple herbivore damage: Beet armyworm and whitefly feeding on cotton plants. J. Chem. Ecol. 2003, 29, 2539-2550. [CrossRef] [PubMed]

7. DeMoraes, C.M.; Mescher, M.C.; Tumlinson, J.H. Caterpillar-induced nocturnal plant volatiles repel conspecific females. Nature 2001, 410, 577-580. [CrossRef] [PubMed]

8. Arimura, G.I.; Kopke, S.; Kunert, M.; Volpe, V.; David, A.; Brand, P.; Dabrowska, P.; Maffei, M.E.; Boland, W. Effects of feeding Spodoptera littoralis on lima bean leaves: IV. Diurnal and nocturnal damage differentially initiate plant volatile emission. Plant Physiol. 2008, 146, 965-973. [CrossRef] [PubMed] 
9. Martini, X.; Kuhns, E.H.; Hoyte, A.; Stelinski, L.L. Plant volatiles and density-dependent conspecific female odors are used by Asian citrus psyllid to evaluate host suitability on a spatial scale. Arthropod-Plant Interact. 2014, 8, 453-460. [CrossRef]

10. Zhang, N.X.; VanWieringen, D.; Messelink, G.J.; Janssen, A. Herbivores avoid host plants previously exposed to their omnivorous predator Macrolophus pygmaeus. J. Pest Sci. 2019, 92, 737-745. [CrossRef]

11. Brilli, F.; Ciccioli, P.; Frattoni, M.; Prestininzi, M.; Spanedda, A.F.; Loreto, F. Constitutive and herbivore-induced monoterpenes emitted by Populus $x$ euroamericana leaves are key volatiles that orient Chrysomela populi beetles. Plant Cell Environ. 2009, 32, 542-552. [CrossRef]

12. Arimura, G.; Kost, C.; Boland, W. Herbivore-induced, indirect plant defences. BBA-Mol. Cell Biol. Lipids 2005, 1734, 91-111. [CrossRef]

13. Degenhardt, D.C.; Lincoln, D.E. Volatile emissions from an odorous plant in response to herbivory and methyl jasmonate exposure. J. Chem. Ecol. 2006, 32, 725-743. [CrossRef]

14. Cai, X.M.; Sun, X.L.; Dong, W.X.; Wang, G.C.; Chen, Z.M. Herbivore species, infestation time, and herbivore density affect induced volatiles in tea plants. Chemoecology 2014, 24, 1-14. [CrossRef]

15. Maffei, M.E.; Mithoefer, A.; Boland, W. Before gene expression: Early events in plant-insect interaction. Trends Plant Sci. 2007, 12, 310-316. [CrossRef] [PubMed]

16. Diezel, C.; VonDahl, C.C.; Gaquerel, E.; Baldwin, I.T. Different lepidopteran elicitors account for cross-talk in herbivory-induced phytohormone signaling. Plant Physiol. 2009, 150, 1576-1586. [CrossRef]

17. Loughrin, J.H.; Manukian, A.; Heath, R.R.; Turlings, T.C.; Tumlinson, J.H. Diurnal cycle of emission of induced volatile terpenoids by herbivore-injured cotton plant. Proc. Natl. Acad. Sci. USA 1994, 91, 18336-18340. [CrossRef]

18. Mattiacci, L.; Rocca, B.A.; Scascighini, N.; D’Alessandro, M.; Hern, A.; Dorn, S. Systemically induced plant volatiles emitted at the time of "danger". J. Chem. Ecol. 2001, 27, 2233-2252. [CrossRef]

19. Shiojiri, K.; Ozawa, R.; Kugimiya, S.; Uefune, M.; VanWijk, M.; Sabelis, M.W.; Takabayashi, J. Herbivore-specific, densitydependent induction of plant volatiles: Honest or "cry wolf" signals? PLoS ONE 2010, 5, 1-11. [CrossRef] [PubMed]

20. Xiu, C.L.; Xu, B.; Pan, H.S.; Zhang, W.; Yang, Y.Z.; Lu, Y.H. Volatiles from Sophora japonica flowers attract Harmonia axyridis adults (Coleoptera: Coccinellidae). J. Integr. Agric. 2019, 18, 873-883. [CrossRef]

21. Kappers, I.F.; Hoogerbrugge, H.; Bouwmeester, H.J.; Dicke, M. Variation in herbivory-induced volatiles among cucumber (Cucumis sativus L.) varieties has consequences for the attraction of carnivorous natural enemies. J. Chem. Ecol. 2011, 37, 150-160. [CrossRef]

22. Ingegno, B.L.; Pansa, M.G.; Tavella, L. Plant preference in the zoophytophagous generalist predator Macrolophus pygmaeus (Heteroptera: Miridae). Biol. Control 2011, 58, 174-181. [CrossRef]

23. Benelli, G.; Revadi, S.; Carpita, A.; Giunti, G.; Raspi, A.; Anfora, G.; Canale, A. Behavioral and electrophysiological responses of the parasitic wasp Psyttalia concolor (Szepligeti) (Hymenoptera: Braconidae) to Ceratitis capitata-induced fruit volatiles. Biol. Control 2013, 64, 116-124. [CrossRef]

24. Lu, Y.H.; Wu, K.M.; Jiang, Y.Y.; Xia, B.; Li, P.; Feng, H.Q.; Wyckhuys, K.A.; Guo, Y.Y. Mirid bug outbreaks in multiple crops correlated with wide-scale adoption of Bt cotton in China. Science 2010, 328, 1151-1154. [CrossRef]

25. Luo, S.P.; Li, H.M.; Lu, Y.H.; Zhang, F.; Haye, T.; Kuhlmann, U.; Wu, K.M. Functional response and mutual interference of Peristenus spretus (Hymenoptera: Braconidae), a parasitoid of Apolygus lucorum (Heteroptera: Miridae). Biocontrol Sci. Technol. 2014, 24, 247-256. [CrossRef]

26. Lu, Y.H.; Qiu, F.; Feng, H.Q.; Li, H.B.; Yang, Z.C.; Wyckhuys, K.A.; Wu, K.M. Species composition and seasonal abundance of pestiferous plant bugs (Hemiptera: Miridae) on Bt Cotton in China. Crop Prot. 2008, 27, 465-472. [CrossRef]

27. Luo, S.P.; Zhang, F.; Wu, K.M. Effect of temperature on the reproductive biology of Peristenus spretus (Hymenoptera: Braconidae), a biological control agent of the plant bug Apolygus lucorum (Hemiptera: Miridae). Biocontrol Sci. Technol. 2015, 25, 1410-1425. [CrossRef]

28. Loivamaeki, M.; Mumm, R.; Dicke, M.; Schnitzler, J.P. Isoprene interferes with the attraction of bodyguards by herbaceous plants. Proc. Natl. Acad. Sci. USA 2008, 105, 17430-17435. [CrossRef]

29. Lloyd, G.R.; Stone, N. Method for identification of spectral targets in discrete frequency infrared spectroscopy for clinical diagnostics. Appl. Spectrosc. 2015, 69, 1066-1073. [CrossRef]

30. Tzin, V.; Hojo, Y.; Strickler, S.R.; Bartsch, L.J.; Archer, C.M.; Ahern, K.R.; Zhou, S.; Christensen, S.A.; Galis, I.; Mueller, L.A.; et al. Rapid defense responses in maize leaves induced by Spodoptera exigua caterpillar feeding. J. Exp. Bot. 2017, 68, 4709-4723. [CrossRef]

31. Anderson, P.; Jonsson, M.; Morte, U. Variation in damage to cotton affecting larval feeding preference of Spodoptera littoralis. Entomol. Exp. Appl. 2001, 101, 191-198. [CrossRef]

32. Girling, R.D.; Stewart, J.A.; Dherbecourt, J.; Staley, J.T.; Wright, D.J.; Poppy, G.M. Parasitoids select plants more heavily infested with their caterpillar hosts: A new approach to aid interpretation of plant headspace volatiles. Proc. R. Soc. B Biol. Sci. 2011, 278, 2646-2653. [CrossRef]

33. Maeda, T.; Takabayashi, J. Production of herbivore-induced plant volatiles and their attractiveness to Phytoseius persimilis (Acari: Phytoseiidae) with changes of Tetranychus urticae (Acari: Tetranychidae) density on a plant. Appl. Entomol. Zool. 2001, 36, 47-52. [CrossRef] 
34. Uefune, M.; Nakashima, Y.; Tagashira, E.; Takabayashi, J.; Takagi, M. Response of Wollastoniella rotunda (Hemiptera: Anthocoridae) to volatiles from eggplants infested with its prey Thrips palmi and Tetranychus kanzawai: Prey species and density effects. Biol. Control 2010, 54, 19-22. [CrossRef]

35. Bawin, T.; DeBacker, L.; Dujeu, D.; Legrand, P.; Megido, R.C.; Francis, F.; Verheggen, F.J. Infestation level influences oviposition site selection in the tomato leafminer Tuta absoluta (Lepidoptera: Gelechiidae). Insects 2014, 5, 877-884. [CrossRef]

36. DeBacker, L.; Megido, R.C.; Fauconnier, M.L.; Brostaux, Y.; Francis, F.; Verheggen, F. Tuta absoluta-induced plant volatiles: Attractiveness towards the generalist predator Macrolophus pygmaeus. Arthropod-Plant Interact. 2015, 9, 465-476. [CrossRef]

37. Turlings, T.C.; Erb, M. Tritrophic interactions mediated by herbivore-induced plant volatiles: Mechanisms, ecological relevance, and application potential. Annu. Rev. Entomol. 2018, 63, 433-452. [CrossRef] [PubMed]

38. Zhang, L.; Lu, G.; Huang, X.; Guo, H.; Su, X.; Han, L.; Zhang, Y.; Qi, Z.; Xiao, Y.; Cheng, H. Overexpression of the caryophyllene synthase gene GhTPS1 in cotton negatively affects multiple pests while attracting parasitoids. Pest Manag. Sci. 2020, 76, 1722-1730. [CrossRef] [PubMed]

39. Huang, X.Z.; Kou, J.F.; Jing, W.X.; Han, X.Q.; Liu, D.F.; Ghasemzadeh, S.; Sun, P.; Shi, W.P.; Zhang, Y.J. Transcriptomic and metabolomic reprogramming in cotton after Apolygus lucorum feeding implicated in enhancing recruitment of the parasitoid Peristenus spretus. J. Pest. Sci. 2021, in press. [CrossRef]

40. Radhika, V.; Kost, C.; Bartram, S.; Heil, M.; Boland, W. Testing the optimal defence hypothesis for two indirect defences: Extrafloral nectar and volatile organic compounds. Planta 2008, 228, 449-457. [CrossRef] [PubMed]

41. Zhou, S.; Lou, Y.R.; Tzin, V.; Jander, G. Alteration of plant primary metabolism in response to insect herbivory. Plant Physiol. 2015, 169, 1488-1498. [CrossRef] [PubMed]

42. Ponzio, C.; Papazian, S.; Albrectsen, B.R.; Dicke, M.; Gols, R. Dual herbivore attack and herbivore density affect metabolic profiles of Brassica nigra leaves. Plant Cell Environ. 2017, 40, 1356-1367. [CrossRef]

43. Pasquale, C.; Rieta, G.; Ninae, F.; Camille, P.; Icke, M.D.; Guerrier, E.M. The effect of rearing history and aphid density on volatile-mediated foraging behaviour of Diaeretiella rapa. Ecol. Entomol. 2019, 44, 255-264.

44. Zalucki, M.P.; Clarke, A.R.; Malcolm, S.B. Ecology and behavior of first instar larval lepidoptera. Annu. Rev. Entomol. 2002, 47, 361-393. [CrossRef] [PubMed]

45. Pan, H.; Tena, A.; Xiu, C.; Liu, B.; Lu, Y.; Desneux, N. Floral feeding increases diet breadth in a polyphagous mirid. J. Pest. Sci. 2019, 92, 1089-1100. [CrossRef]

46. Lou, Y.G.; Ma, B.; Cheng, J.A. Attraction of the parasitoid Anagrus nilaparvatae to rice volatiles induced by the rice brown planthopper Nilaparvata lugens. J. Chem. Ecol. 2005, 31, 2357-2372. [CrossRef] 